\title{
Potential Application of Silica Aerogel Granules for Cleanup of Accidental Spillage of Various Organic Liquids
}

\author{
Vinayak G. Parale ${ }^{1}$, Dinesh B. Mahadik ${ }^{1}$, Mahendra S. Kavale ${ }^{1}$, A. Venkateswara Rao ${ }^{1 *}$, \\ Pratap B. Wagh ${ }^{2}$, Satish C. Gupta ${ }^{2}$
}

${ }^{1}$ Air Glass Laboratory, Department of Physics, Shivaji University, Maharashtra, India; ${ }^{2}$ Applied Physics Division, Bhabha Atomic Research Centre, Mumbai, India.

Email: *avrao2012@gmail.com

Received April 26 ${ }^{\text {th }}$, 2011; revised May 30 ${ }^{\text {th }}$, 2011; accepted September $23^{\text {rd }}, 2011$.

\begin{abstract}
The experimental work has been carried out to study the absorption-desorption properties of the silica aerogels, for their use in oil spill cleanup application. For these studies, silica aerogel granules were prepared by two step acidbase catalyzed sol-gel process, involving ambient pressure drying of alcogels, were made use for absorption \& desorption studies of different organic liquids. The optimal molar ratio of precursors tetraethoxysilane (TEOS):Methanol (MeOH):Oxalic acid: $\mathrm{NH}_{4} \mathrm{OH}: \mathrm{NH}_{4} \mathrm{~F}:$ trimethylchlorosilane (TMCS) was kept constant at 1:16.5:0.71:0.58:0.60:0.98, respectively. In all, four alkanes, four aromatic compounds, four alcohols and three oils were used for absorption and desorption studies of organic liquids. The absorption capacity of aerogel sample was quantified by measuring the mass of the organic liquid absorbed by unit mass of the aerogel sample. The hydrophobic aerogel granules showed a very high uptake capacity and high rate of uptake. The desorption of solvents and oils was studied by keeping the liquid absorbed aerogel granules at various temperatures and weighing them at regular time intervals until all the absorbed liquid got totally desorbed. The Fourier transform infrared spectroscopy analysis showed that the aerogel structure was not much affected by the solvent absorption, while the oil absorption led to the shrinkage, resulting in a dense structure after desorption.
\end{abstract}

Keywords: Oil Spill Cleanup, Ambient Pressure Drying, Hydrophobic, Silica Aerogels

\section{Introduction}

Marine oil spills are the most important threat to the coastal environment and ecosystem of the sea. Moreover, oil spills are responsible for the great loss of energy resources. They are formed mainly by occasional accidental episodes of super tankers, oil rig drilling, war and natural events. Therefore, the ecological disasters resulting from oil spills have created a great need for cost effective cleanup systems. In recent years large numbers of studies have been devoted to oil spill cleanup [1]. A wide range of materials for oil remediation have actually been employed such as dispersants, absorbents, solidifiers and booms [2-8]. Dispersants simply disperse the oil to accelerate the oil and separate it from the water by absorption. Absorbents collect the oil and separate it from the water by absorption. Absorbent materials are attractive for oil spill cleanup application because of the possibility of collection and complete removal of the oil from the oil spill site. The addition of absorbents to oil spill areas facilitates a change from liquid to semi-solid phase and once this change is achieved, the removal of the oil by removal of the absorbent structure then becomes much easier. Solidifiers react with the oil to form a cohesive, solidified mass that floats on water and Booms are used to trap the oil in small area [9].

The properties for good absorbent materials include hydrophobicity and oleophilicity, high uptake capacity, reusability and biodegradability of the absorbents [10]. Advanced material engineering techniques can structure surfaces that allow dynamic tuning of their wettability all the way from superhydrophobic (i.e. repelling) behaviour to almost complete wetting (i.e. super hydrophilic) but these surfaces only work with high-surface-tension liquids [11]. Almost all organic liquids that are everywhere 
in human environment such as oils, solvents, detergents, etc. have quite low surface tensions and thus easily wet the hydrophobic surfaces. Silica aerogels possess low surface energy; therefore it absorbs liquid which possess surface energy less than the surface energy of aerogels [12].

Silica aerogels, a class of mesoporous materials with extremely high porosities ( 98\%) and high surface area (700 - $1600 \mathrm{~m}^{2} / \mathrm{g}$ ), have found potential applications in thermal insulation, low dielectric constant thin layer, low refractive index glass, catalysts, absorbents etc. [13]. Aerogels are usually synthesized by hydrolysis and condensation of the silicon alkoxide followed by supercritical drying of the solvent from a wet gel. In supercritical state of the solvent, the surface tension becomes zero and hence the resulting aerogels found to be monolithic [14]. However, supercritical process is expensive and dangerous, which puts the restriction on the commercial scale processing of the aerogels [15]. Therefore, attempts have been made to synthesize the cost effective silica aerogel by atmospheric pressure drying method involves mechanical shaking of alcogels, to accelerates the solvent exchange process [16]. This method is commercially attractive as a safer process compared to supercritical drying process; however the total processing period is only $36 \mathrm{~h}$, which helps to reduce the production cost of silica aerogel granules. The only disadvantage of ambient pressure drying is the retrieved aerogel are in the form of pieces instead of monolithic. But for oil spill cleanup application, monolithic aerogels becomes pieces after absorption of oil, therefore it is better to use pieces of aerogels for oil spill cleanup application. The hydrophobic silica aerogels were found to be excellent absorbers of organic liquids with high uptake capacity therefore it can be used for oil spill cleanup application. In absorption and desorption studies all, fifteen solvents: four alkanes, four aromatic compounds, four alcohols and three oils have been used to study the absorbtion capacity and the rate of desorption of the liquids of the hydrophobic aerogels.

\section{Materials and Methods}

\subsection{Experimental Procedure}

The synthesis of an aerogel involves two major steps: 1) the preparation of the alcogel by two step acid-base catalyzed sol-gel process and 2) the ambient pressure drying of the wet gel to remove the solvent.
Initially, the tetraethoxysilane (TEOS) was diluted in methanol $(\mathrm{MeOH})$ solvent and was partially hydrolyzed with water under acidic conditions with oxalic acid $(0.0005 \mathrm{M})$. The sol was stirred for $1 \mathrm{~h}$ and kept for hydrolysis for $6 \mathrm{~h}$. The molar ratio of TEOS:MeOH:Oxalic acid: $\mathrm{NH}_{4} \mathrm{OH}: \mathrm{NH}_{4} \mathrm{~F}$ :TMCS was kept constant at 1:16.5: 0.71:0.58:0.60:0.98 respectively. After hydrolysis base catalysts were added in the sol and after gelation, gel kept in oven for 45 min., for strengthening the gel network. After aging of the alcogels, they were cut into small cubic pieces. The methanol was decanted out and hexane was added. The methanol in the gel was exchanged with hexane at $50^{\circ} \mathrm{C}$. The alcogels in hexane was shaked at $120 \mathrm{rpm}$ for $4 \mathrm{~h}$ in a shaker (Remi instruments, Mumbai, India). To make the gels hydrophobic, the gels were immersed in a liquid mixture containing 7\% TMCS of the 93\% hexane for silylation and kept in oven for $16 \mathrm{~h}$ at $50^{\circ} \mathrm{C}$. The unreacted TMCS was exchanged with the solvent by keeping again in the shaker for $4 \mathrm{~h}$ at $50^{\circ} \mathrm{C}$ with $120 \mathrm{rpm}$ speed. Finally, the alcogel pieces along with a little solvent were kept in the bottle. The bottle was covered with aluminum foil with 8 - 10 small pin holes to allow the evaporation of the solvent. These bottles were kept in the oven at $50^{\circ} \mathrm{C}$ for $1 \mathrm{~h}$ and at $150^{\circ} \mathrm{C}$ for $2 \mathrm{~h}$. The retrieved aerogels were cooled to room temperature and used for absorption and desorption studies of various organic liquids.

\subsection{Reaction Mechanism}

The hydrolysis and condensation of methanol diluted tetraethoxysilane (TEOS) in the presence of oxalic acid, $\mathrm{NH}_{4} \mathrm{OH}$ and $\mathrm{NH}_{4} \mathrm{~F}$ is shown in the following chemical reactions:

\subsubsection{Hydrolysis}

$$
\mathrm{Si}\left(\mathrm{OC}_{2} \mathrm{H}_{5}\right)_{4}+4 \mathrm{H}_{2} \mathrm{O} \stackrel{\mathrm{C}_{2} \mathrm{H}_{2} \mathrm{O}_{4}}{\longrightarrow} \mathrm{Si}(\mathrm{OH})_{4}+4 \mathrm{C}_{2} \mathrm{H}_{5} \mathrm{OH}
$$

\subsubsection{Condensation}

$$
\begin{aligned}
& \mathrm{Si}(\mathrm{OH})_{4}+(\mathrm{OH})_{4} \mathrm{Si} \stackrel{\mathrm{NH}_{4} \mathrm{OH}+\mathrm{NH}_{4} \mathrm{~F}}{\longrightarrow} \\
& (\mathrm{OH})_{3} \mathrm{Si}-\mathrm{O}-\mathrm{Si}(\mathrm{OH})_{3}+\mathrm{H}_{2} \mathrm{O}
\end{aligned}
$$

The hydrophobicity was achieved by surface chemical modification of alcogels by $7 \%$ trimethylchlorosilane (TMCS) in hexane. The surface modification of the gel with TMCS is shown in the reaction (3) $[12,17]$.

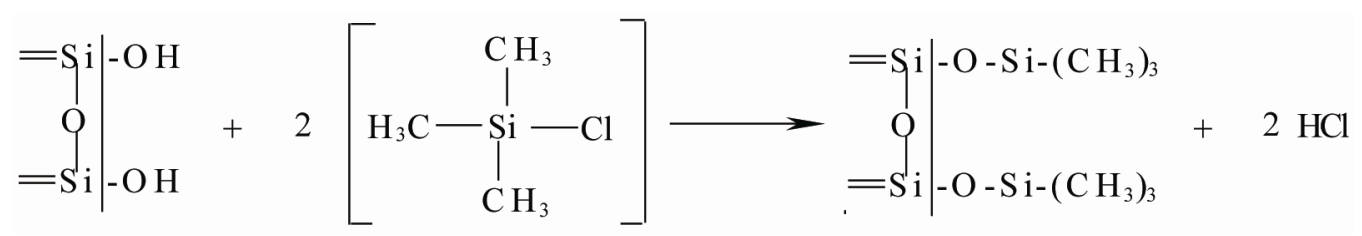




\subsection{Methods of Characterization}

The apparent density, \% of volume shrinkage, \% of porosity and pore volume of the as prepared silica aerogels were measured using following formulae [15].

$$
\begin{gathered}
\% \text { of volume shrinkage }=\left(1-\frac{V_{a}}{V_{g}}\right) \times 100 \\
\% \text { of porosity }=\left(1-\frac{\rho_{b}}{\rho_{s}}\right) \times 100 \\
\text { Pore volume }=\left(\frac{1}{\rho_{b}}-\frac{1}{\rho_{s}}\right) \times 100
\end{gathered}
$$

where, $V_{a}$ and $V_{g}$ are the volumes of the aerogel and alcogel respectively, $\rho_{s}$ is the skeletal density $\left(\sim 1.9 \mathrm{~g} \cdot \mathrm{cm}^{-3}\right)$ and $\rho_{b}$ is the apparent density.

Here, density measurements of granules were conducted on the basis of mass of granules per unit volume of $\mathrm{cm}^{3}$. Volume shrinkage of aerogels measured with respect to alcogel volume which is assumed as $100 \%$. The aerogel granules were used to study absorption and desorption capacity for different organic liquids. The contact angle of water with surface of aerogel was measured by using the contact angle meter (Rame-Hart, Model 500 F-1, USA). The surface chemical modification of the aerogels was studied by using the Fourier Transform Infrared Spectroscopy (Perkin Elmer Instruments, Spectrum one, USA). The thermal stability of the aerogel samples was characterized by TGA and DTA analysis in the air atmosphere. The surface morphological studies carried out by using field emission scanning electron microscopy (FESEM). The absorption capacity of the aerogel sample was studied by weighing the aerogel sample by using a microbalance $\left(10^{-5} \mathrm{~g}\right.$ accuracy) before absorption, immediately after absorption, and after total evaporation of the liquid from the sample.

\section{Results and Discussion}

\subsection{Absorption Study of Organic Liquids by the Hydrophobic Aerogels}

The ambiently dried TEOS based silica aerogels possess low density $\left(0.062 \mathrm{~g} / \mathrm{cm}^{3}\right)$, high porosity $(96.7 \%)$, pore volume $\left(15.2 \mathrm{~cm}^{3} / \mathrm{g}\right)$ and water contact angle $\left(145^{\circ}\right)$. These aerogel granules were used to study absorption and desorption capacity for different organic liquids. The absorption capacity of the aerogels was quantified by measuring the difference between mass of aerogel granules before and after absorption of organic liquid. For the present studies different, 15 organic solvents were studied which includes, viz., four alkanes, four aromatic compounds, four alcohols, and three different kinds of oil samples. The alkanes include hexane, heptane, octane and cyclohexane; the aromatic compounds include benzene, toluene, xylene and acetone; the alcohols include methanol, ethanol, propanol and isobutanol; and the three oils include petrol, diesel and engine oil.

Table 1 shows the mass of various organic solvents, alcohols and oils absorbed by unit mass of the aerogel

\begin{tabular}{|c|c|c|c|c|}
\hline Organic liquid & Surface Tension $(\mathrm{mN} / \mathrm{m})$ & 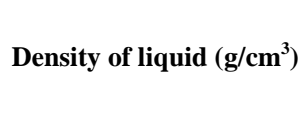 & $\begin{array}{c}\text { Calculated } \\
\text { Mass absorbed } \\
\mathrm{q}=\rho \times \mathrm{V}(\mathrm{g} / \mathrm{g})\end{array}$ & $\begin{array}{c}\text { Experimental } \\
\text { Mass absorbed } \\
\text { (g/g) }\end{array}$ \\
\hline Hexane & 18.4 & 0.649 & 10.47 & 10.00 \\
\hline Heptane & 20.3 & 0.671 & 10.82 & 12. 00 \\
\hline Octane & 21.62 & 0.694 & 11.20 & 12.50 \\
\hline Cyclohexane & 24.95 & 0.799 & 12.89 & 12.84 \\
\hline Methanol & 22.5 & 0.783 & 12.63 & 12.14 \\
\hline Ethanol & 22.3 & 0.722 & 11.65 & 12.60 \\
\hline Propanol & 23.78 & 0.795 & 12.83 & 13.65 \\
\hline Iso-Butanol & 24.6 & 0.802 & 12.94 & 14.20 \\
\hline Benzene & 29 & 0.868 & 14.00 & 14.52 \\
\hline Toluene & 29 & 0.858 & 13.84 & 13.90 \\
\hline Xylene & 28.9 & 0.870 & 14.04 & 13.58 \\
\hline Acetone & 25.20 & 0.790 & 12.75 & 12.49 \\
\hline Petrol & 26 & - & - & 10.84 \\
\hline Diesel & 30 & - & - & 11.56 \\
\hline Engine oil & 31.60 & 0.905 & 14.60 & 12.91 \\
\hline
\end{tabular}
sample. It is observed that, the mass of iso-butanol ab-

Table 1. Mass of various organic liquid absorbed by unit mass of the aerogel sample. 
sorbed was maximum (14.20 g) and methanol was minimum (12.14 g) among the alcohols. Among the alkanes, the mass of cyclohexane absorbed was maximum (12.84 g), while that of hexane absorbed was minimum $(10 \mathrm{~g})$. In case of the aromatic compounds the mass of xylene absorbed was minimum (13.58 g) and that of benzene was maximum (14.52 g). Similarly, mass of acetone absorbed by the aerogel granules was $12.49 \mathrm{~g}$. In oils, the mass of petrol absorbed was minimum (10.84 g) and that of engine oil was maximum $(12.91 \mathrm{~g})$. The absorption capacity of the aerogel for each organic liquid can be calculated by using the relation,

$$
q=\rho \times V
$$

where, $q$ is the mass of organic liquid absorbed by the aerogel, $\rho$ be the density of aerogel sample and $V$ is the pore volume of aerogel. From table it is observed that the calculated and experimental values of mass of organic liquid absorbed by unit mass of aerogel granules are nearly same.

The mass of the organic liquid absorbed by an aerogel mainly depends upon the surface chemical composition of absorbent and surface tension of the liquid. The surface modified silica alcogels possess non-polar $-\mathrm{CH}_{3}$ bonds at the ends of the $\mathrm{SiO}_{2}$ network. This can be achieved by modifying surface with TMCS silylating reagent, which converts its hydrophilic nature into hydrophobic one. The organic liquids taken in the absorption studies possess low surface tension. As per Neumann's theory of wettability [18], the material will absorb those liquids which possess low surface tension than the surface tension of the material, which indicate that the wettability of solid depends upon the surface tension of the liquid used. The organic liquids possess very low surface tension and therefore, they wet the aerogel surface fully and get easily absorbed. Since the aerogels are highly porous (96.7\%), hence the liquid absorption is due to the capillarity action. Aerogels are already proved to be promising candidate in the field of oil spill cleanup application [19]. Generally, aerogels are prepared by supercritical drying of alcogels, but monolithic aerogels possess high cost of production, therefore, attempt have been made to prepare low cost aerogels. The absorption capacity of ambiently dried silica aerogels shows nearly equal as compared with the supercritically dried aerogels. Figure 1(a) shows the photograph of beaker contains water and engine oil and Figure 1(b) indicates that only oil present in water is absorbed by the aerogels while Figure 1(c) shows that the oil isolated by the aerogels from water. It is clear that, the silica aerogel granule absorbs organic liquids around 13 to 15 times of its own mass. Therefore, silica aerogels can be used for oil spill cleanup applications.

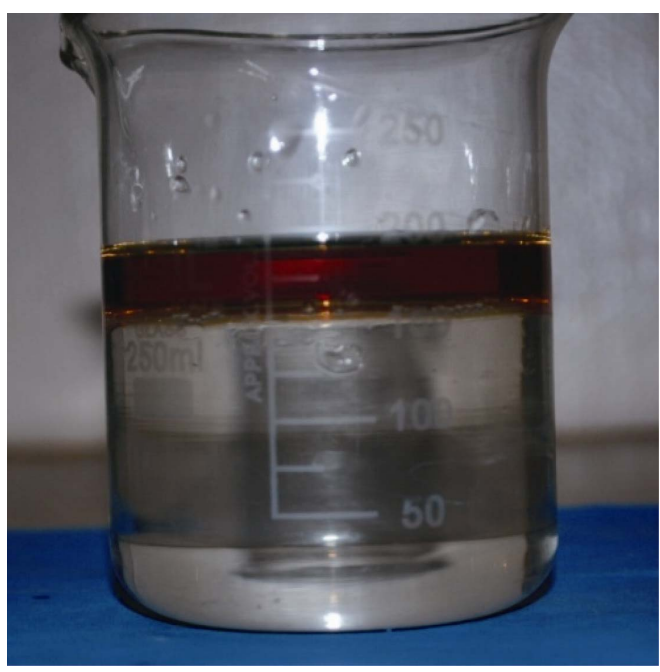

(a)

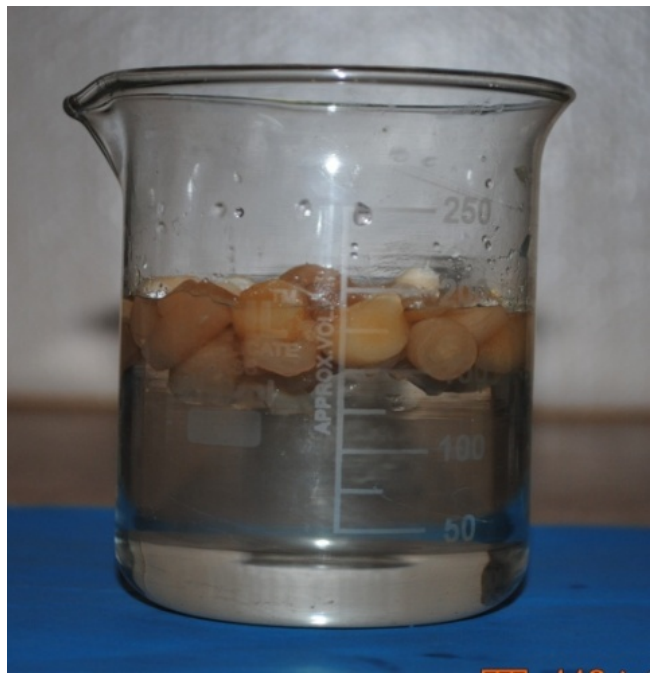

(b)

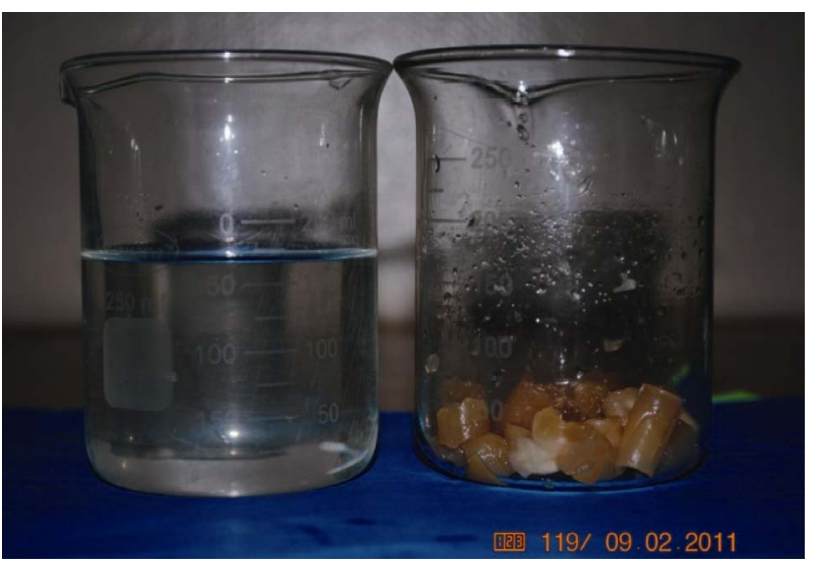

(c)

Figure 1. (a) Engine oil and water in the beaker, (b) shows that only oil present in water is absorbed by the aerogel granules, (c) shows the separated water and oil absorbed aerogels in beakers. 


\subsection{Desorption Rate of Organic Liquids at Different Temperature}

The time taken by the liquid for complete evaporation from the aerogel pores starting from the moment of absorption is called desorption time. It was observed that the organic liquids evaporate from the aerogel surface gradually. The rate of desorption was estimated by measuring the mass of the liquid absorbed by the aerogels at regular time intervals till the liquid got totally evaporated and the original mass of the aerogel was restored and hence faster would be the evaporation. The variation of surface tension of the liquid with its temperature [9], is given by the following relation,

$$
\gamma_{t}=\gamma_{0}(1-\alpha t)
$$

where $\gamma_{0}$ and $\gamma_{t}$ are surface tension at $0^{\circ} \mathrm{C}$ and $t^{\circ} \mathrm{C}$, respectively, $\alpha$ is the temperature coefficient of surface tension for the liquid. Figure 2 shows the desorption time versus the temperature for petrol, propanol, benzene and heptane. The surface tension of all the liquids decreases linearly with the rising temperature. It is observed that as temperature increases desorption time decreases. It was also, observed that desorption time increased from shorter chain (hexane) to the longer chain (octane) organic liquids. This may be due to the fact that the evaporation of liquids takes place in two stages. In the first stage, molecules of liquid are brought from the interior up to the surface, overcoming the surface tension effect. During the second stage, they vaporize from the surface depending on the vapour pressure of the liquid. Also, the vapour pressure decreases with increase in the chain length and molecular weight of the organic liquid. The vapour pressure $\left(226 \mathrm{~mm}\right.$ of $\mathrm{Hg}$ at $25^{\circ} \mathrm{C}$ ) for hexane is very high which led to faster evaporation and that for cyclohexane is very less $\left(24.05 \mathrm{~mm}\right.$ of $\mathrm{Hg}$ at $\left.25^{\circ} \mathrm{C}\right)$, and

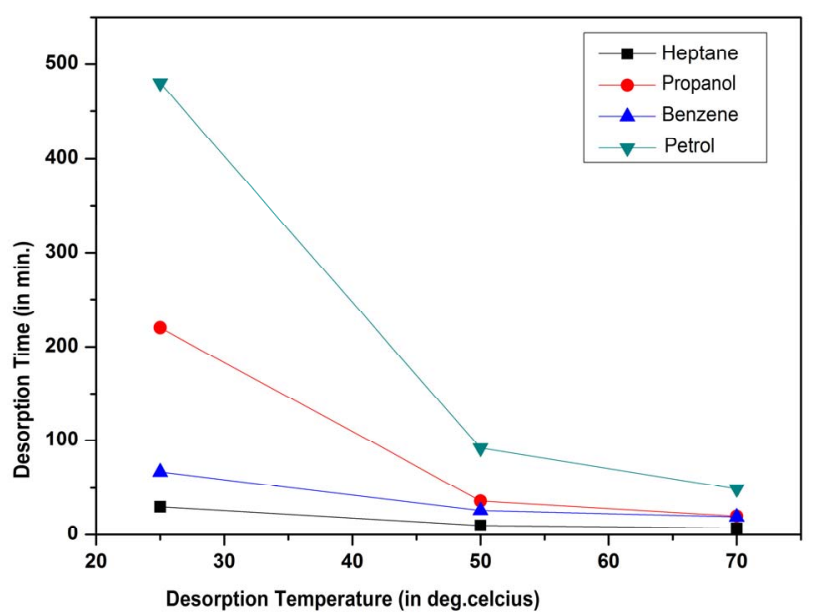

Figure 2. Desorption rate of TEOS based silica aerogels at different temperatures. hence desorption time for cyclohexane is more. As a result it would be easy for the liquid molecules to come out of the aerogel pores at higher temperatures due to higher temperature gradient. But in case of oils more time is required to evaporate for oil, from the aerogels due to the oil with low vapour pressure.

The $30 \%$ volume shrinkage and some cracks is observed after absorption of organic liquid and after desorption, aerogels regains approximately $80 \%$ of its original volume observed. During the evaporation of liquid from the pores of the aerogel it exerts a capillary pressure on the walls of the pore and is given by the Laplace equation [20],

$$
P_{r}=\frac{-2 \gamma \cos \theta}{r_{\text {pore }}}
$$

where $\gamma$ the surface tension of the liquid, $\theta$ is the contact angle of the liquid with the aerogel surface and $r$ is the radius of the pore. Since, the organic liquid fully wets the surface, $\theta=0$ and therefore, the capillary pressure equation becomes,

$$
P_{r}=\frac{-2 \gamma}{r_{p o r e}}
$$

The surface tension of is around $20 \mathrm{mN} / \mathrm{m}$ (depending on the liquid) and pore radius of the aerogel is order of tens of $\mathrm{nm}$, the capillary pressure is very high which is of the order of $106 \mathrm{~Pa}$. Therefore, the solvent is in tension and it induces a compressive stress ( 106 Pa) on the aerogel network. As a result, the aerogel shrinks during desorption. As the liquid evaporates from the aerogel pores, gradually the inward pull reduces due to decrease in the pressure gradient and hence the aerogel starts to regain its size. When liquid gets evaporated fully from all the pores, the aerogel springs back to its original shape and size retaining all its physical and hydrophobic properties. Therefore, these ambiently dried silica aerogels can be re-used at least for thrice.

\subsection{Comparative FTIR Studies of the Aerogels before Absorption and after Desorption}

Figure 3 shows the FTIR spectrum of silica aerogels before absorption of any organic liquid while Figure 4 shows the FTIR spectra of the silica aerogel after desorption of propanol, petrol, heptane, engine oil, and benzene at room temperature $28^{\circ} \mathrm{C}$. The prominent peak at around $1100 \mathrm{~cm}^{-1}$ in both figures, is due to the asymmetric bending mode of silicon dioxide. The both FTIR spectra showed strong peaks at $845 \mathrm{~cm}^{-1}, 1100 \mathrm{~cm}^{-1}$ and 2970 $\mathrm{cm}^{-1}$ corresponding to Si-C, Si-O-Si and C-H bonds respectively. Very small peaks observed at $3400 \mathrm{~cm}^{-1}$ and $1640 \mathrm{~cm}^{-1}$ corresponds to $\mathrm{O}-\mathrm{H}$ bonding which indicates 


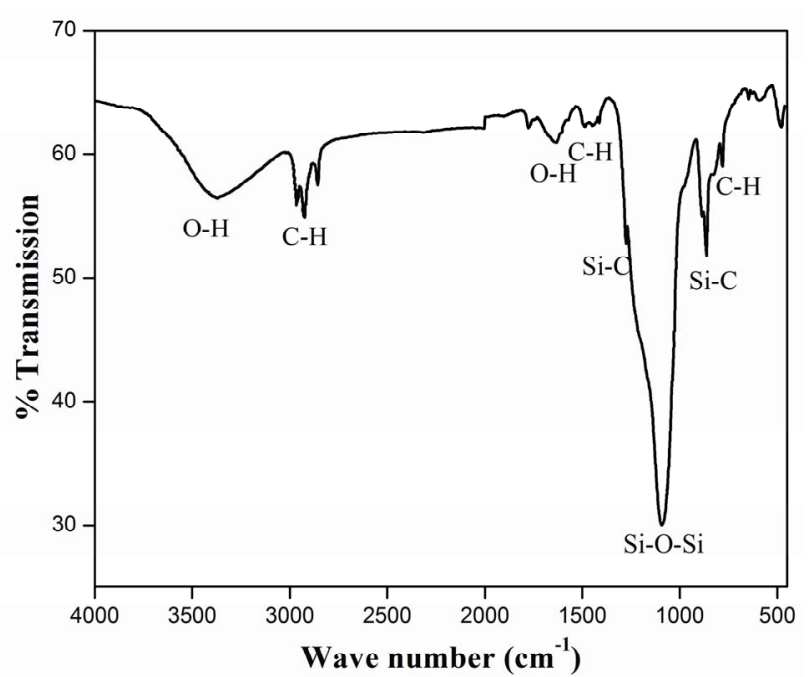

Figure 3. FTIR spectra of silica aerogel before absorption of solvents and oils.

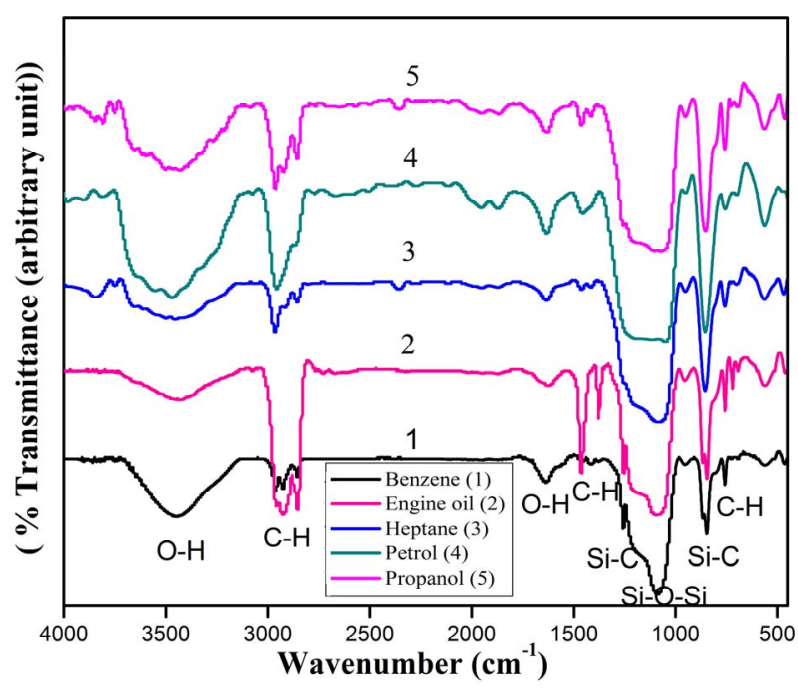

Figure 4. FTIR spectra of silica aerogel after desorption of solvents and oils.

the hydrophobic nature of the aerogels [21]. From Figure 4 it is observed that the peak intensity of $\mathrm{C}-\mathrm{H}$ bonding is increased for petrol and engine oil as compared to the other organic liquids. Therefore, it can be concluded that engine oil and petrol has not been totally desorbed from the aerogel sample.

\subsection{Surface Morphological Studies of Aerogels}

The field emission scanning electron microscopy (FESEM) image of the two-dimensional surface morphology of the retrieved silica aerogels is as shown in Figure 5. From the FESEM it is clear that there is uniformity and homogeneity of $\mathrm{SiO}_{2}$ particle and porous network [22]. Such uniform and homogeneous nano-structured particle

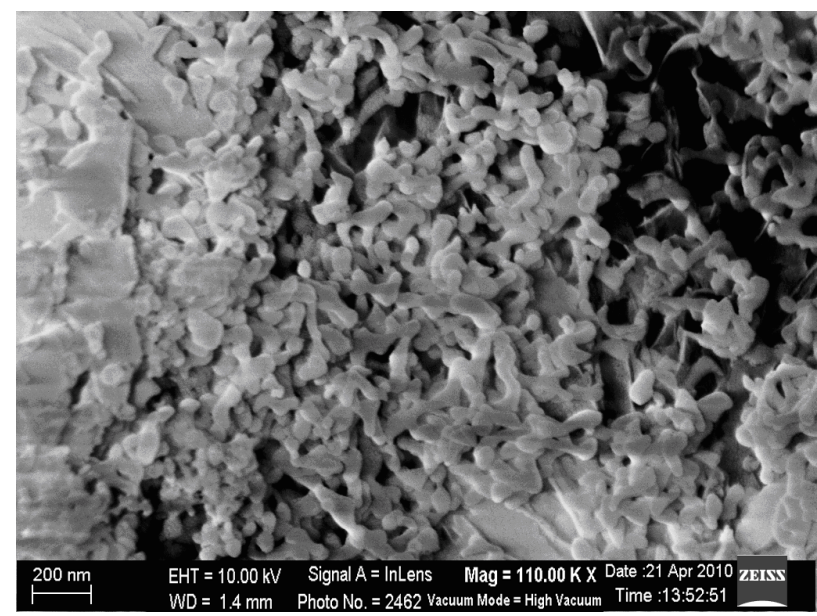

Figure 5. FESEM image of the aerogel before absorption of oil or organic liquids.

and pores results in high absorption of the organic liquids. From few selected areas of the material under scan shown statistical average colloidal particle size of the silica found around 30 to $40 \mathrm{~nm}$ and the pore size around 70 to $100 \mathrm{~nm}$. The silylation process might be leading to increase in pore sizes of the silica network. The surface morphology is important as the wettability of a surface is dependent on its chemical composition and surface topography.

\subsection{Thermal Stability Analysis of Silica Aerogels}

Figure 6 shows the typical TGA and DTA profiles for the TMCS modified silica aerogel sample. The noticeable weight loss was observed at around $380^{\circ} \mathrm{C}$ in TGA curve, accompanied with an exothermic peak in the DTA curve. The sudden weight loss at around $380^{\circ} \mathrm{C}$ is due to the decomposition of alkyl $\left(-\mathrm{CH}_{3}\right)$ groups where as the exothermic peak in DTA curve is due to the oxidation of

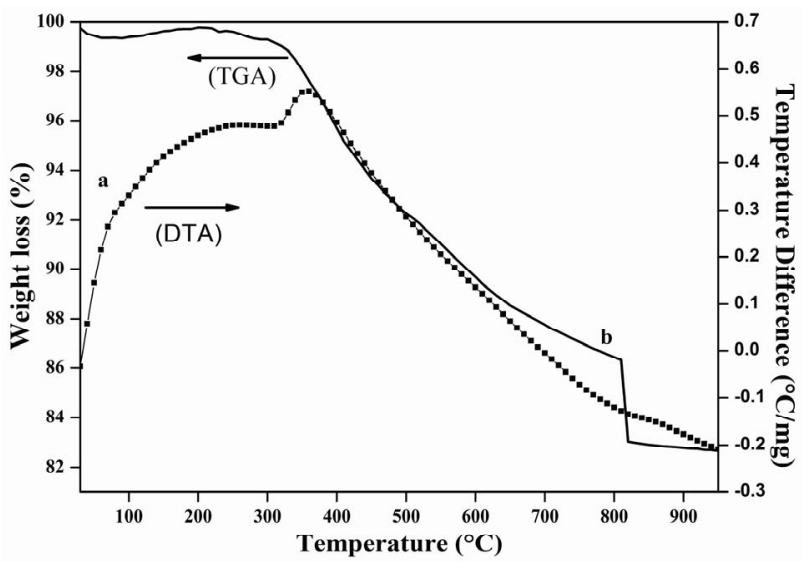

Figure 6. Thermo gravimetric and differential thermal analysis (TG-DTA) of aerogels. 
alkyl groups. It indicates that the thermal stability of TMCS modified silica aerogels is up to $380^{\circ} \mathrm{C}$ and above this temperature the aerogel will show hydrophilic nature [23]. Hence present study reveals that the hydrophobic aerogels are thermally stable up to $380^{\circ} \mathrm{C}$ and are suitable for their use for absorption and desorption of various organic liquids present in water.

\section{Conclusions}

The ambient pressure dried TEOS based hydrophobic silica aerogel granules were obtained by the two-step sol-gel process using TMCS as the hydrophobic reagent for surface chemical modification. The optimal molar ratio of precursor chemicals TEOS:MeOH:Oxalic acid: $\mathrm{NH}_{4} \mathrm{OH}: \mathrm{NH}_{4} \mathrm{~F}$ :TMCS was kept constant at 1:16.5:0.71: 0.58:0.60:0.98, respectively. The retrieved silica aerogel granules were deployed for absorption and desorption studies of various organic liquids. The absorption studies reveal that the hydrophobic silica aerogel granules absorb organic liquids approximately 13 times and different oils nearly 12 times with respect own mass of silica aerogel materials. The mass absorbed by aerogels were found to be depend upon the density and surface tension of the given organic liquids and oils. The desorption time of aerogel decreased as temperature increased and aerogel regains its original structure around $80 \%$ after the total desorption of organic liquid. In case of oil samples particularly diesel and engine oil, some traces might be present in samples and their presence has been verified from FT-IR studies. SEM studies of aerogel shows the uniform and homogeneous nano-structured pores results in high uptake capacity of organic liquids due to capillarity action. This indicates that ambiently dried silica aerogel granules can be used to clean the organic liquids in case of there is accidental spillage during transport of vehicles on roads as well as accidental spillage of organic liquids in sea water. The hydrophobic nature of aerogels can be retained up to temperature of $380^{\circ} \mathrm{C}$ as indicated by the thermal analysis studies and hence such aerogels can efficiently applied for potential application of absoption and desorption of accidental spillage of organic liquids and oils.

\section{Acknowledgements}

The authors are highly thankful to the Board of Research in Nuclear Sciences (BRNS), Department of Atomic Energy (DAE), Mumbai, India for the funding this work under major research project No. 2008/37/47/BRNS/ 2502 dated 28/01/2009. The authors D. B. Mahadik and M. S. Kavale are highly grateful to the DAE-BRNS Mumbai for the Junior Research Fellowship.

\section{REFERENCES}

[1] A. Bayat, S. F. Aghamiri, A. Moheb and G. R. Vakili-
Nezhaad, "Oil Spill Cleanup from Sea Water by Sorbent Materials,” Chemical Engineering Technology, Vol. 28, 2005, pp. 1525-1528. doi:10.1002/ceat.200407083

[2] M. Fingas, "Oil Spills and Their Cleanup," Chemical Industry, Vol. 24, 1995, pp. 1005-1008.

[3] A. Bieser, “The Mainstream of Physics,” Second Edition, Addison Wesley Publishing Company Inc., 1962.

[4] R. D. Delaune, C. W. Lindau and A. Jugsujinda, "Effectiveness of Nochar Solidifier Polymer in Removing Oil from Open Water in Coastal Wetlands," Spill Science Technology Bulletin, Vol. 5, 1999, pp. 357-359. doi:10.1016/S1353-2561(99)00081-X

[5] C. H. Teas, S. Kalligeros, F. Zanikos, S. Stoumas, E. Lois and G. Anastopoulos, "Investigation of the Effectiveness of Absorbent Materials in Oil Spills Clean up,” Desalination, Vol. 140, No. 3, 2001, pp. 259-264. doi:10.1016/S0011-9164(01)00375-7

[6] J. W. Doerffer, "Oil Spill Response in the Marine Environment,” First Edition, Pergamon Press, Oxford, 1992.

[7] R. R. Lessard and G. Demarco, "The Significance of Oil Dispersants,” Spill Science Technology Bulletin, Vol. 6, No. 1, 2000, pp. 59-68. doi:10.1016/S1353-2561(99)00061-4

[8] N. Hering, K. Schriber, R. Riedel, O. Lichtenberger and J. Woltersodorf, "Synthesis of Polymeric Precursors for the Formation of Nanocrystalline Ti-C-N/Amorphous Si-C-N Composites,” Applied Organometallic Chemistry, Vol. 15, No. 10, 2001, pp. 879-886. doi:10.1002/aoc.241

[9] A. V. Rao, N. D. Hegade and H. Hirashima, “Absorption and Desorption of Organic Liquids in Elastic Superhydrophobic Silica Aerogels," Journal Colloids and Interface Science, Vol. 305, No. 1, 2007, pp. 124-132. doi:10.1016/j.jcis.2006.09.025

[10] M. O. Adebajo, R. L. Frost, J. T. Kloprogge, O. Carmody and S. Kokot, "Porous Materials for Oil Spill Cleanup: A Review of Synthesis and Absorbing Properties,” Journal of Porous Materials, Vol. 10, No. 3, 2003, pp. 159-170. doi:10.1023/A:1027484117065

[11] J. L. Gurav, A. V. Rao, D. Y. Nadargi and H. H. Park, "Ambient Pressure Dried TEOS-Based Silica Aerogels: Good Absorbents of Organic Liquids,” Journal of Material Science, Vol. 45, 2010, pp. 503-510. doi:10.1007/s10853-009-3968-8

[12] D. B. Mahadik, A. V. Rao, A. P. Rao, P. B. Wagh, S. V. Ingale and S. C. Gupta, "Effect of Concentration of Trimethylchlorosilane (TMCS) and Hexamethyldisilazane (HMDZ) Sylilating Agents on Surface Free Energy of Silica Aerogels," Journal Colloids and Interface Science, Vol. 356, No. 1, 2011, pp. 298-302. doi:10.1016/j.jcis.2010.12.088

[13] K. Sinko, "Influence of Chemical Conditions on the NanoPorous Structure of Silicate Aerogels," Materials, Vol. 3, No. 1, 2010, pp. 704-740. doi:10.3390/ma3010704

[14] A. V. Rao, S. D. Bhagat, H. Hirashima and G. M. Pajonk, "Synthesis of Flexible Silica Aerogels Using Methyltrimethoxysilane (MTMS) Precursor,” Journal Colloids and 
Interface Science, Vol. 300, No. 1, 2006, pp. 279-285.

[15] P. M. Shewale, A. V. Rao and A. P. Rao, "Effect of Different Trimethyl Silylating Agents on the Hydrophobic and Physical Properties of Silica Aerogels,” Journal of Applied Surface Science, Vol. 254, No. 21, 2008, pp. 6902-6907.

[16] D. B. Mahadik, A. V. Rao, R. Kumar, S. V. Ingale, P. B. Wagh and S. C. Gupta, "Reduction of Processing Time by Mechanical Shaking of the Ambient Pressure Dried TEOS Based Silica Aerogels," Journal of Porous Materials, Article in Press.

[17] A. P. Rao and A. V. Rao, "Modifying the Surface Energy and Hydrophobicity of the Low-Density Silica Aerogels through the Use of Combinations of Surface-Modification Agents," Journal of Material Science, Vol. 45, 2010, pp. 51-63. doi:10.1007/s10853-009-3888-7

[18] F. H. Newman and V. H. L. Searle, "The General Properties of Matter,” 5th Edition, Orient Longmans, London, 1957.

[19] T. Dand-Vu, J. Hupka and J. Drzymala, "Impact of Roughness on Hydrophobicityof Particles Measured by the Washburn Method," Physicochemical Problems of
Mineral Processing, Vol. 40, 2006, pp. 45-52.

[20] P. M. Shewale, A. V. Rao, A. P. Rao and S. D. Bhagat, "Synthesis of Transparent Silica Aerogels with Low Density and Better Hydrophobicity by Controlled Sol-Gel Route and Subsequent Atmospheric Pressure Drying," Journal Sol-Gel Science and Technology, Vol. 49, No. 3, 2009, pp. 285-292.

[21] A. V. Rao, M. M. Kulkarni and S. D. Bhagat, "Transport of Liquids Using Superhydrophobic Aerogels,” Journal Colloids and Interface Science, Vol. 285, No. 1, 2005, pp. 413-418.

[22] N. D. Hegde and A. V. Rao, "Physical Properties of Methyltrimethoxysilane Based Elastic Silica Aerogels Prepared by the Two Step Sol-Gel Process,” Journal of Material Science, Vol. 42, No. 16, 2007, pp. 6965-6971. doi:10.1007/s10853-006-1409-5

[23] A. V. Rao and R. R. Kalesh, "Organic Surface Modification of TEOS Based Silica Aerogels Synthesized by Coprecursor and Derivatization Methods,” Journal Sol-Gel Science and Technology, Vol. 30, 2004, pp. 141-147. doi:10.1023/B:JSST.0000039498.61813.9e 